BMJ Open

Sport \&

Exercise

Medicine

\title{
Evaluation of determinants of walking fitness in patients attending cardiac rehabilitation
}

\author{
Patrick Doherty, Jassas FM Alotaibi
}

To cite: Doherty $P$, Alotaibi JFM. Evaluation of determinants of walking fitness in patients attending cardiac rehabilitation. BMJ Open Sport Exerc Med 2017;2:e000203. doi:10.1136/bmjsem-2016000203

Accepted 9 January 2017

CrossMark

Department of Health Sciences, University of York, York, UK

Correspondence to Dr Jassas FM Alotaibi; jfma500@york.ac.uk

\section{ABSTRACT}

Aim This study aims to investigate the ability of patients' baseline characteristics to predict the distance walked during the incremental shuttle walk test (ISWT) in the cardiac rehabilitation (CR) population and to produce reference values to guide practice.

Methods Secondary analysis was conducted on National Audit Cardiac Rehabilitation data collected between 2010 and 2015. Patients $(n=8863)$ were included if they were aged $\geq 18$ years and had a recorded ISWT score assessed before starting CR. Stepwise regression was used to identify factors predicting the ISWT distance. Age, gender, body mass index, height, weight; presence of hypertension, dyslipidemia or diabetes; smoking and physical activity were independent variables. ISWT distance was the dependent variable. The 25th, 50th and 75th percentiles of the ISWT distance were used as reference values.

Results Age and gender explained $27 \%$ of the variance of the distance covered in the ISWT $\left(R^{2}=0.27\right.$, adjusted $R^{2}=0.27$,Standard Error of the Estimate (SEE) $=148.7, p<0.001)$. Reference values using age and gender categories were developed.

Conclusion Age and gender were the significant factors for predicting the walking fitness in the $\mathrm{CR}$ population, with age being the best predictor. The age and gender reference values produced represent a potentially valuable tool to be used in the clinical setting.

\section{INTRODUCTION}

Assessing physical fitness at baseline and end of programme in patients attending cardiac rehabilitation (CR) is strongly recommended in clinical guidelines and national standards. ${ }^{1-3}$ Assessing a patient's fitness level at the beginning of the programme enables the appropriate intensity of exercise to be prescribed, determines the level of supervision and monitoring required and allows for the assessment of the effectiveness of the intervention. ${ }^{34}$

Using laboratory maximal tests on treadmills or cycle ergometers to assess cardiorespiratory fitness by directly measuring the maximal oxygen uptake ( $\mathrm{Vo}_{2}$ max or $\mathrm{Vo}_{2}$ peak) is regarded as the gold standard. However, these tests are not widely available. ${ }^{15}$ Compared with the gold standard methods, functional fitness walk tests are simple and safe to use and are a reasonable surrogate measure of fitness. ${ }^{6}$ In the UK, the most commonly used field test in $\mathrm{CR}$ and chronic obstructive pulmonary disease patients is the incremental shuttle walk test (ISWT), which is an objective test widely used in clinical settings to assess the extent of physical fitness. ${ }^{5} 6$ This type of test is shown to be reliable and strongly correlated with the cardiopulmonary exercise test (CPET). ${ }^{7}{ }^{8}$ The ISWT is a submaximal, incremental, externally paced test that evaluates physical fitness based on the distance covered during the assessment. ${ }^{6} 8$ The recommended protocol is a $20 \mathrm{~min}$ test followed by a $30 \mathrm{~min}$ rest period before the test is repeated. The best outcome of the two tests is then recorded. However, in routine clinical practice, the ISWT is generally performed just once despite emerging research suggesting that the learning effect may influence the distance achieved as evidenced through a second baseline test. ${ }^{9}$ Most CR programmes struggle to carry out even a single baseline fitness test, ${ }^{10}$ which makes undertaking a second test unrealistic. To date, very few studies have tried to establish reference values as a comparison with the first ISWT attempt, and where it has been attempted, the sample size has been insufficient within the proposed categories. ${ }^{11} 12$

Healthy individuals have been shown to walk double the distance of patients with cardiac disease during the ISWT (600-800 $\mathrm{m}$ vs $300-400 \mathrm{~m}$, respectively). ${ }^{11}$ Predicting the distance covered during the ISWT has been attempted in several studies in healthy populations ${ }^{13-17}$; however, to date, only two studies have been published using a CR 
population. ${ }^{11} 12$ These two studies conducted by Pepera et al (2013) and Cardoso et al (2016) explained $20 \%$ and $25 \%$, respectively, of the variance in distance walked, and the latter study attempted to produce reference values for CR patients. Age, height, body mass index (BMI) and the presence of diabetes were found to be significant predictors in the study by Cardoso et al while Pepera et al found only height and BMI to be significant. However, the limited number of female participants and the small number of centres used limit the generalisability and clinical usefulness of these results. The need for reference values remains important as they could help reduce or even eliminate the need to do the ISWT a second time and could be used as feedback for patients in respect of their level of fitness.

The aims of this study were (1) to identify any additional important predictors, beyond age and gender, of the distance covered during the ISWT at baseline, (2) to produce reference values for the distance walked by CR patients during the ISWT and (3) to propose an approach for benchmarking performance following the test. This information has the potential to be used to guide clinical practitioners' expectations of the patients' performance in an ISWT and help them set realistic CR goals.

\section{METHODS}

This observational study was reported according to the Strengthening the Reporting of Observational Studies in Epidemiology. ${ }^{18}$

\section{Data collection}

Secondary analysis was conducted using anonymised individual patient data from the National Audit Cardiac Rehabilitation (NACR) database from 2010 to 2015. NACR is a national quality-assurance project which is designed to ensure that the optimum CR outcomes are achieved with patients with cardiovascular disease and that the CR programmes follow good practice as defined by the clinical minimum standards. ${ }^{10} 19$ The NACR data are collected under 251 approval by National Health Service Digital. The data are entered by the centres themselves into the NACR database. This database includes information concerning the patients' demographic and anthropometric details, initial event, risk factors, treatment, medications, physical activity status and clinical outcomes following CR. ${ }^{10}$

Patients were included in the analysis if they were adults (>18 years); were postmyocardial infarction, coronary artery bypass grafting, percutaneous coronary intervention or valve surgery patients; had already been assessed at baseline before starting CR; had undertaken the ISWT and hence their fitness had been assessed and their age, gender, height, weight, BMI and comorbidities had also been recorded.

\section{Incremental shuttle walk test}

In this test, the patient walks a 10 metre course, known as a shuttle. The patient walks continuously back and forth between two cones and an audio signal dictates the walking speed. The test has 12 levels, at each level the number of shuttles the patient is required to walk increases. The test ends when the patient completes the 12 levels, achieves $80 \%$ of the maximum heart rate $\left(\mathrm{HR}_{\max }=220-\right.$ age $)$, rate perceived exertion (RPE) is more than 15 , is no longer able to keep up with the audio signal, or is too breathless. When the patient finishes the test, the number of shuttles, and hence the distance covered, is recorded. ${ }^{2021}$

\section{Statistical analysis}

Data were presented as mean and standard deviation (SD). An independent t-test was used to determine the differences between men and women at baseline. Pearson's correlation was used to study the relationship between outcome and the potential predicted variables. By accounting for age, the difference in the distance walked between men and women was assessed using two-way ANOVA. Stepwise multiple regression analysis was used to investigate which factors predict ISWT distance. Age, gender, BMI, height and weight; presence of hypertension, dyslipidemia or diabetes; smoking (yes, no) and physical activity level at baseline based on meeting the $150 \mathrm{~min} /$ week recommendation (yes, no) were entered into the regression as independent variables. The key outcome was the distance covered in metres during the ISWT. Prior to the analysis, it was decided to consider only variables which explained more than $5 \%$ of the variance. The assumptions of the regression model were checked and there were no violations.

The 25th, 50th and 75th percentiles of the distance walked were produced to provide reference values. Data were analysed using Statistical Package for Social Science V.23. A p value $<0.05$ is considered to be significant.

\section{RESULTS}

The study population comprised patients from 48 centres in the UK who had undertaken the ISWT as a baseline assessment (figure 1). Of the 8863 patients, 6893 $(77.78 \%)$ were male and 1970 (23.22\%) were female.

The patient demographics and the baseline characteristics are summarised in table 1 . The mean age of the group was $63.26 \pm 11.09$ years and ranged from 20 to 99 years; the mean BMI was $27.86 \pm 4.56 \mathrm{~kg} / \mathrm{m}^{2}$ (table 1). There was a significant difference between the ages of men and women $(62.7 \pm 11$ vs $65.11 \pm 11.24$, $\mathrm{p}<0.001)$, respectively. Men were also significantly taller $(174.27 \pm 7.00)$ than women $(160.16 \pm 6.64)$. The mean distance covered by the overall sample was $358.11 \pm 174.40 \mathrm{~m}$. After taking account of age in the analysis, the men walked significantly further than women $\quad(384.24 \pm 175.41 \mathrm{~m}$ and $266.58 \pm 135.94 \mathrm{~m}$, 
Number of patients performing (ISWT) with complete records of age and gender at baseline assessment

$\mathrm{N}=8863$

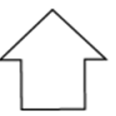

Number of patients performing Incremental Shuttle Walk Test (ISWT) as a baseline test $\mathrm{N}=8880$

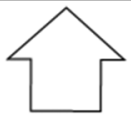

Number of patients who started CR with valid baseline assessment

$\mathrm{N}=11,7241$

Figure 1 Patient flowchart for cardiac rehabilitation.

$\mathrm{p}<0.001$, respectively). The most prevalent comorbidities among the participants were hypertension, dyslipidemia and diabetes. Seven per cent of the participants were smokers (table 1).

Stepwise regression analysis using age and gender explained $27 \%$ of the variance in the distance covered during the ISWT. Age was the best predictor explaining $21 \%$ of the variance in the ISWT distance $\left(\mathrm{r}=0.455, \quad \mathrm{R}^{2}=0.21, \quad\right.$ adjustedR $\mathrm{R}^{2}=0.21 \quad \mathrm{SEE}=155.4$, $\mathrm{p}<0.001)$. The strength of prediction was further improved by adding gender $\left(\mathrm{R}^{2}=0.27\right.$, adjusted $\left.\mathrm{R}^{2}=0.27, \mathrm{SEE}=148.7, \mathrm{p}<0.001\right)($ table 2$)$.

\begin{tabular}{|c|c|c|c|}
\hline $\begin{array}{l}\text { Factor } \\
\text { Sample size }\end{array}$ & $\begin{array}{l}\text { Total sample } \\
\qquad n=(8863)\end{array}$ & $\begin{array}{c}\text { Male } \\
\mathrm{n}=6893(77.8 \%)\end{array}$ & $\begin{array}{c}\text { Female } \\
n=1970(23.2 \%)\end{array}$ \\
\hline Age (years) & $63.26 \pm 11.09$ & $62.73 \pm 11$ & $65.10 \pm 11.25$ \\
\hline Height (cm) & $171.14 \pm 9.11$ & $174.27 \pm 7$ & $160.16 \pm 6.64$ \\
\hline Weight (kg) & $81.80 \pm 15.51$ & $84.78 \pm 14.4$ & $71.40 \pm 14.8$ \\
\hline BMI $\left(k g / m^{2}\right)$ & $27.86 \pm 4.56$ & $27.89 \pm 4.29$ & $27.81 \pm 5.42$ \\
\hline ISWT $(m)^{*}$ & $358.11 \pm 174.40$ & $384.24 m \pm 175.41$ & $266.58 \pm 135.94$ \\
\hline Hypertension (\%) & 40.1 & 39.0 & 43.0 \\
\hline Dyslipidemia (\%) & 31.3 & 31.2 & 31.8 \\
\hline Diabetes (\%) & 16.0 & 16.2 & 15.5 \\
\hline Physical activity (\%) & 40.5 & 43.0 & 33.0 \\
\hline Smokers (\%) & 7.3 & 7.2 & 7.7 \\
\hline MI (\%) & 8.6 & 7.3 & 13.0 \\
\hline $\mathrm{PCl}(\%)$ & 60.1 & 60.8 & 57.3 \\
\hline CABG (\%) & 22.1 & 24.4 & 14.2 \\
\hline Valve surgery (\%) & 9.2 & 7.4 & 15.6 \\
\hline
\end{tabular}

BMI, body mass index; CABG, coronary artery bypass grafting; ISWT, incremental shuttle walk est; MI, myocardial infarction; PCI, percutaneous coronary intervention. 
Table 2 Predictor variables for distance walked in the ISWT

\begin{tabular}{lccc}
\hline Variable & Unstandardised coefficient (b) & $\mathbf{9 5 \%} \mathbf{C l}$ & $\mathbf{p ~ V a l u e ~}$ \\
\hline Age & -6.95 & -7.23 to -6.67 & $>0.001$ \\
Gender & 101.18 & 93.70 to 108.66 & $>0.001$ \\
Constant & 719.20 & 699.80 to 738.60 & $>0.001$ \\
\hline
\end{tabular}

ISWT, incremental shuttle walk test

The equation developed in this study to predict the ISWT distance was:

$719.2-(6.95 \times$ xage $)+(101.18 x g e n d e r)($ Where male $=1$ and female $=0$ )

None of the following variables; BMI, height, weight, smoking, physical activity level or the presence of hypertension, dyslipidemia and diabetes made no considerable contribution as predictors to the model.

Tables 3 and 4 show the age-related reference values according to patient gender. In each age band, the distances walked by women were significantly shorter than those walked by men. There was an inverse relationship between the values of distance walked and age bands for both men and women. The youngest age group ( $\leq 44$ years) for both genders walked the farthest and the oldest age group $(\geq 80)$ walked the shortest distance, and this remained true for each centile value.

\section{DISCUSSION}

In this study, the factors which best predict the distance covered in the ISWT and the reference values for this distance at the baseline of the CR assessment were produced using national level data from routine

Table 3 Centile values for total distance walked during the ISWT by female patients assessed at entry to outpatient cardiac rehabilitation

\begin{tabular}{lcccccc}
\hline $\begin{array}{l}\text { Women } \\
\text { age band } \\
\text { (years)* }\end{array}$ & Sample & $\begin{array}{c}\text { C } \\
\mathbf{2 5}\end{array}$ & $\begin{array}{c}\mathbf{C} \\
\mathbf{5 0}\end{array}$ & $\begin{array}{c}\mathbf{C} \\
\mathbf{7 5}\end{array}$ & Mean & SD \\
\hline$\leq 44$ & 88 & 300 & 375 & 500 & 402 & 167 \\
\hline $45-49$ & 115 & 270 & 350 & 440 & 366 & 151 \\
\hline $50-54$ & 141 & 250 & 330 & 440 & 342 & 151 \\
\hline $55-59$ & 236 & 220 & 290 & 390 & 310 & 142 \\
\hline $60-64$ & 254 & 200 & 270 & 360 & 285 & 125 \\
\hline $65-69$ & 379 & 180 & 250 & 340 & 262 & 116 \\
\hline $70-74$ & 337 & 150 & 220 & 290 & 228 & 103 \\
\hline $75-79$ & 271 & 130 & 190 & 260 & 200 & 91 \\
$\geq 80$ & 149 & 100 & 160 & 200 & 160 & 86 \\
\hline
\end{tabular}

*Age bands (years), in 5-year increments.

$\mathrm{C}$, centile value for distance walked in metre; ISWT, incremental shuttle walk test. clinical practice. The main findings of this study were that age and gender were significant predictors of the variance in distance walked during the ISWT.

The results indicated that age was the best predictor explaining $21 \%$ of the variance in the distance covered and was inversely correlated with fitness. It was reported that the direction of this correlation might be due to changes which occur in parallel with ageing such as cardiovascular responses related to a decrease in the maximal heart rate, arteriovenous oxygen difference, ejection fraction and a reduction in maximal cardiac output, ${ }^{22-24}$ or the decrease in maximal oxygen uptake and a reduction in both muscle mass and muscle strength. ${ }^{13}$ This $21 \%$ value is in agreement with the result reported in the study by Cardoso $e t a l^{11}$ in female participants, higher than the $4 \%$ reported in a previous study in healthy subjects. ${ }^{14}$ This study found that gender explained $6 \%$ of the variance, which is in agreement with the study by Dourado et al; however, gender was reported to explain more in the study by Cardoso et al $(11 \%)$.

The current results explained more of the variance in distance walked than that reported in previous studies in a similar CR population. ${ }^{11}{ }^{12}$ The study

Table 4 Centile values for total distance walked during the ISWT by male patients assessed at entry to outpatient cardiac rehabilitation

\begin{tabular}{|c|c|c|c|c|c|c|}
\hline $\begin{array}{l}\text { Men } \\
\text { Age band } \\
\text { (years)* }\end{array}$ & Sample & $\begin{array}{c}C \\
25\end{array}$ & $\begin{array}{c}C \\
50\end{array}$ & $\begin{array}{c}\text { C } \\
75\end{array}$ & Mean & SD \\
\hline$\leq 44$ & 357 & 420 & 520 & 630 & 519 & 193 \\
\hline $45-49$ & 473 & 370 & 510 & 620 & 497 & 182 \\
\hline $50-54$ & 798 & 340 & 460 & 570 & 470 & 182 \\
\hline 55-59 & 985 & 330 & 420 & 540 & 435 & 176 \\
\hline $60-64$ & 1085 & 280 & 380 & 490 & 391 & 156 \\
\hline 65-69 & 1209 & 270 & 360 & 450 & 366 & 141 \\
\hline $70-74$ & 926 & 220 & 330 & 420 & 321 & 134 \\
\hline $75-79$ & 701 & 180 & 250 & 330 & 264 & 118 \\
\hline$\geq 80$ & 359 & 140 & 200 & 280 & 214 & 107 \\
\hline
\end{tabular}

*Age bands (years), in 5-year increments.

$\mathrm{C}$, centile value for distance walked in metres; ISWT, incremental shuttle walk test 
conducted recently by Cardoso et al reported that age, height and the presence of diabetes explained $24 \%$ and $25 \%$ of the variance in the distance walked by female and male participants, respectively, while in men, an additional significant predictor was BMI. However, in that study, the results for the female participants were based on a very small sample of patients with diabetes $(n=35)$, whereas, in this study $(n=8863)$, the presence of diabetes did not contribute significantly to the explanation of the variance in either men or women. In the earlier study by Pepera $e t a l^{12}$, height and BMI explained $20 \%$ of this variance; however, unlike in the current study, neither age nor gender were significant predictors, which might be due to the lower age range of the participants and the small sample of women.

Conversely, the results from this study showed a lower $R^{2}$ value $\left(R^{2}=0.27\right.$, adjusted $R^{2}=0.27$, $\mathrm{SEE}=148.7, \mathrm{p}<0.001)$ than that reported in previous studies where reference equations were developed to predict the distance covered during ISWT in a healthy population. ${ }^{13-17}$ However, the protocol of the ISWT was extended in these studies from 12 to 15 levels to avoid the ceiling effect, ${ }^{13-15}$ whereas in a typical CR patient, achieving a distance over and above the standard ISWT (12 levels) is unlikely. ${ }^{10}$

\section{Reference values}

On the basis of the results obtained from this study, we have created reference values according to age and gender. Age was the stronger predictor and gender, in addition to its modest predictive function, is routinely used in literature to differentiate fitness values. ${ }^{1} 1125$ 26 The practical implications of these reference values are to guide practitioners' expectations about how well patients might perform in an ISWT, to assist in the initial interpretation of the ISWT results to assess the need for a second test, to help patients understand their fitness level in relation to their peers and to set realistic goals to improve their physical condition as part of the CR intervention.

As mentioned previously, there is only one study which has attempted to produce ISWT reference values for the CR population. ${ }^{11}$ Cardoso et al produced reference values for patients who joined the outpatient CR programme based on 547 patients: 132 women and 415 men. The patients were divided into age bands at 5-year intervals from 25 to 90 (13 bands) according to gender. However, the use of these reference values might be considered unrealistic due to the small number of participants, most notably fewer females, which resulted in an average number of approximately 10 participants in each band. In addition, the data were obtained from only four UK hospitals, compared with $48 \mathrm{CR}$ programmes in this study, which might be considered unrepresentative of the general population with cardiac disease.
In this study, we divided the group into nine bands, seven of them at 5-year intervals. The two remaining bands, namely the first and the last band, were larger as we found that there was no significant difference in the mean of the ISWT distance walked between the patients within each of these marginal bands regardless of age. The median distance walked by men and women in the youngest age band $(\leq 44$ years) was $520 \mathrm{~m}$ and $375 \mathrm{~m}$, respectively, which was more than twice the distance walked in the oldest age band ( $\geq 80$ years) at $200 \mathrm{~m}$ for men and $160 \mathrm{~m}$ for women. We used the 25th and 75th percentiles as they are a useful guide for CR practitioners to evaluate baseline score and assist with goal setting as part of core CR delivery.

The major strength of this study was the large sample, covering a wide age range in the CR population suffering from different comorbidities, which was sufficient to enable the analysis. However, the study was not without limitations. Due to the retrospective nature of the study, some significant predictors that were reported in previous studies were not found in the NACR database such as resting heart rate, rate of perceived exertion and hand strength grip, and so these were not taken into consideration. ${ }^{16}$

The normative values proposed in this article assume that the ISWT was carried out in a rigorous way but we are unable to substantiate this. The test is supported by a clinician, and the patient follows the verbal and bleep commands from the ISWT audio recording, which gives some confidence that it was delivered in a consistent manner.

\section{CONCLUSION}

Age and gender were the commonly determined key factors in predicting the ISWT distance in the CR population, with age being the best predictor. The reference values produced in this study represent a valuable tool to be used in a clinical setting. These findings may assist practitioners in their initial expectations of patients' performance in the ISWT, enable them to interpret the test results to better inform patients of their fitness level and potentially aid patients in the setting of realistic CR goals in respect to their walking ability.

\section{Implications for practice}

Reference values in this study have the potential to be used as a tool to help guide CR practitioners' expectations of ISWT performance.

- These values can inform practitioners of the need to perform a second ISWT test.

- Reference values enable CR patients to understand their age and gender-related walking fitness level prior to starting CR, which could help set realistic goals. 
Funding This research was carried out by the British Heart Foundation (BHF) Cardiovascular Care and Education Research Group which is supported by a grant from the BHF (R1680902).

Competing interests None declared.

Provenance and peer review Not commissioned; externally peer reviewed.

Open Access This is an Open Access article distributed in accordance with the terms of the Creative Commons Attribution (CC BY 4.0) license, which permits others to distribute, remix, adapt and build upon this work, for commercial use, provided the original work is properly cited. See: http:// creativecommons.org/licenses/by/4.0/

(c) Article author(s) (or their employer(s) unless otherwise stated in the text of the article) 2017. All rights reserved. No commercial use is permitted unless otherwise expressly granted.

\section{REFERENCES}

1. Arena R, Myers J, Williams MA, et al; American Heart Association Committee on Exercise, Rehabilitation, and Prevention of the Council on Clinical Cardiology, American Heart Association Council on Cardiovascular Nursing. Assessment of functional capacity in clinical and research settings: a scientific statement from the American Heart Association Committee on Exercise, Rehabilitation, and Prevention of the Council on Clinical Cardiology and the Council on Cardiovascular Nursing. Circulation 2007;116:329-43.

2. Piepoli MF, Corrà U, Abreu A, et al; Cardiac Rehabilitation Section of the European Association for Cardiovascular Prevention \& Rehabilitation of the ESC. Challenges in secondary prevention of cardiovascular diseases: a review of the current practice. Int $J$ Cardiol 2015;180:114-9.

3. BACPR. The BACPR Standards and Core Components for Cardiovascular Disease Prevention and Rehabilitation. 2012. British Association for Cardiovascular Prevention and Rehabilitation 2nd edn. http://www.bacpr.com/resources/46C_BACPR_Standards_ and_Core_Components_2012.pdf

4. Mezzani A, Hamm LF, Jones AM, et al; European Association for Cardiovascular Prevention and Rehabilitation American Association of Cardiovascular and Pulmonary Rehabilitation Canadian Association of Cardiac Rehabilitation. Aerobic exercise intensity assessment and prescription in cardiac rehabilitation: a joint position statement of the European Association for Cardiovascular Prevention and Rehabilitation, the American Association of Cardiovascular and Pulmonary Rehabilitation, and the Canadian Association of Cardiac Rehabilitation. J Cardiopulm Rehabil Prev 2012;32:327-50

5. Houchen-Wolloff L, Boyce S, Singh S. The minimum clinically important improvement in the incremental shuttle walk test following cardiac rehabilitation. Eur J Prev Cardiol 2015;22.

6. Singh SJ, Morgan MD, Scott S, et al. Development of a shuttle walking test of disability in patients with chronic airways obstruction. Thorax 1992;47:1019-24.

7. Pepera G, McAllister J, Sandercock G. Long-term reliability of the incremental shuttle walking test in clinically stable cardiovascular disease patients. Physiotherapy 2010;96:222-7.

8. Singh SJ, Puhan MA, Andrianopoulos V, et al. An official systematic review of the European Respiratory Society/American Thoracic
Society: measurement properties of field walking tests in chronic respiratory disease. Eur Respir J 2014;44:1447-78.

9. Jolly K, Taylor RS, Lip GY, et al; BRUM Steering Committee. Reproducibility and safety of the incremental shuttle walking test for cardiac rehabilitation. Int J Cardiol 2008;125:144-5.

10. NACR. The national audit of cardiac rehabilitation annual statistical report 2016. London: British Heart Foundation. 2016. http://www. cardiacrehabilitation.org.uk/docs/BHF_NACR_Report_2016.pdf

11. Cardoso FM, Almodhy M, Pepera G, et al. Reference values for the incremental shuttle walk test in patients with cardiovascular disease entering exercise-based cardiac rehabilitation. J Sports Sci 2017;35:1-6.

12. Pepera G, Cardoso F, Taylor MJ, et al. Predictors of Shuttle Walking Test performance in patients with cardiovascular disease. Physiotherapy 2013:99:317-22.

13. Jürgensen SP, Antunes LC, Tanni SE, et al. The incremental shuttle walk test in older Brazilian adults. Respiration 2011;81:223-8.

14. Dourado VZ, Vidotto MC, Guerra RL. Reference equations for the performance of healthy adults on field walking tests. J Bras Pneumol 2011;37:607-14.

15. Probst VS, Hernandes NA, Teixeira DC, et al. Reference values for the Incremental Shuttle Walking Test. Respir Med 2012;106:243-8.

16. Dourado VZ, Guerra RL, Tanni SE, et al. Reference values for the Incremental Shuttle Walk Test in healthy subjects: from the walk distance to physiological responses. J Bras Pneumol 2013;39:190-7.

17. Harrison SL, Greening NJ, Houchen-Wolloff L, et al. Age-specific normal values for the Incremental Shuttle Walk Test in a healthy British population. J Cardiopulm Rehabil Prev 2013;33:309-13.

18. von Elm E, Altman DG, Egger M, et al; STROBE Initiative. The strengthening the reporting of observational studies in epidemiology (STROBE) statement: guidelines for reporting observational studies. Epidemiology 2007;18:800-4.

19. Doherty $\mathrm{P}$, Harrison AS, Knapton M, et al. Observational study of the relationship between volume and outcomes using data from the national audit of cardiac rehabilitation. Open Heart 2015;2:e000304.

20. Woolf-May K, Ferrett D. Metabolic equivalents during the $10-\mathrm{m}$ shuttle walking test for post-myocardial infarction patients. $\mathrm{Br} J$ Sports Med 2008;42:36-41.

21. Holland $A E$, Spruit MA, Singh SJ. How to carry out a field walking test in chronic respiratory disease. Breathe 2015;11:128-39.

22. Stratton JR, Levy WC, Cerqueira MD, et al. Cardiovascular responses to exercise. effects of aging and exercise training in healthy men. Circulation 1994;89:1648-55.

23. Hossack KF, Bruce RA. Maximal cardiac function in sedentary normal men and women: comparison of age-related changes. J App Physiol Respir Environ Exerc Physiol 1982;53:799-804.

24. Lakoski SG, Barlow CE, Farrell SW, et al. Impact of body mass index, physical activity, and other clinical factors on cardiorespiratory fitness (from the cooper center longitudinal study). Am J Cardiol 2011;108:34-9.

25. Fletcher GF, Balady GJ, Amsterdam E, et al. Exercise standards for testing and training: a statement for healthcare professionals from the American Heart Association. Circulation 2013;128:873-934.

26. Wang CY, Haskell WL, Farrell SW, et al. Cardiorespiratory fitness levels among US adults 20-49 years of age: findings from the 19992004 National Health and Nutrition Examination Survey. Am J Epidemiol 2010;171:426-35. 